\title{
BMJ Open Content and outcomes of narrative medicine programmes: a systematic review of the literature through 2019
}

\author{
Christy DiFrances Remein (D) , ${ }^{1}$ Ellen Childs, ${ }^{2}$ John Carlo Pasco, ${ }^{1}$ \\ Ludovic Trinquart, ${ }^{2}$ David B Flynn, ${ }^{1}$ Sarah L Wingerter, ${ }^{1}$ Robina M Bhasin, ${ }^{1}$ \\ Lindsay B Demers, ${ }^{1}$ Emelia J Benjamin ${ }^{1,2}$
}

To cite: Remein CDiF, Childs E, Pasco JC, et al. Content and outcomes of narrative medicine programmes: a systematic review of the literature through 2019. BMJ Open 2020;10:e031568. doi:10.1136/ bmjopen-2019-031568

- Prepublication history and additional material for this paper are available online. To view these files, please visit the journal online (http://dx.doi. org/10.1136/bmjopen-2019031568).

CDR and EC contributed equally.

Received 09 May 2019

Revised 23 November 2019

Accepted 02 December 2019

Check for updates

(c) Author(s) (or their employer(s)) 2020. Re-use permitted under CC BY-NC. No commercial re-use. See rights and permissions. Published by BMJ.

${ }^{1}$ Boston University School of Medicine, Boston

Massachusetts, USA

${ }^{2}$ Boston University School of Public Health, Boston, Massachusetts, USA

Correspondence to Dr Ellen Childs; echilds@bu.edu

\section{ABSTRACT}

Objectives Narrative medicine (NM) incorporates stories into health sciences paradigms as fundamental aspects of the human experience. The aim of this systematic review is to answer the research question: how effective is the implementation and evaluation of NM programmes in academic medicine and health sciences? We documented objectives, content and evaluation outcomes of NM programming to provide recommendations for future narrative-based education.

Methods We conducted a systematic review of literature published through 2019 using five major databases: PubMed, Embase, PsycINFO, ERIC and MedEdPORTAL. Eligible NM programming included textual analysis/close reading of published literature and creative/reflective writing. Qualifying participants comprised individuals from academic medicine and health sciences disciplines. We reviewed and categorised programme goals, content and evaluation activities to assess participant satisfaction and programme efficacy. Two members of the research team assessed the risk of bias, independently screening records via a two-round, iterative process to reach consensus on eligibility.

Results of 1569 original citations identified, we selected 55 unique programmes (described in 61 records). In all, $41(75 \%)$ programmes reported a form of evaluation; evaluation methods lacked consistency. Twenty-two programmes used quantitative evaluation (13 well described), and 33 programmes used qualitative evaluation (27 well described). Well-described quantitative evaluations relied on 32 different measures (7 validated) and showed evidence of high participant satisfaction and pre-post improvement in competencies such as relationshipbuilding, empathy, confidence/personal accomplishment, pedagogical skills and clinical skills. An average of $88.3 \%$ of participants agreed or strongly agreed that the programme had positive outcomes. Qualitative evaluation identified high participant satisfaction and improvement in competencies such as relationship-building, empathy, perspective-taking/reflection, resilience and burnout detection/mitigation, confidence/personal accomplishment, narrative competence, and ethical inquiry.

Conclusion Evaluation suggests that NM programming leads to high participant satisfaction and positive outcomes across various competencies. We suggest best practices and innovative future directions for programme implementation and evaluation.
Strengths and limitations of this study

- This systematic review synthesises current evidence regarding evaluation of 55 unique narrative medicine programmes.

- We synthesised both quantitative and qualitative programme evaluations.

- The reporting quality of evaluation methods and results frequently was inadequate.

- Evaluation design was highly variable, with the majority lacking assessment of long-term impact.

\section{INTRODUCTION}

Narrative medicine (NM) is a framework for medicine and health sciences that values individuals' stories and experiences as integral aspects of the lived experience of health and illness. Historically, the fields of knowledge associated with medicine/science and narrative/humanities were more integrated until about the 19th century. ${ }^{1}$ Likewise, the proliferation of specialisation within medicine is a relatively modern conceptualisation that has necessitated advanced technical training, leaving less space in educational curricula for the cultivation of humanistic disciplines. ${ }^{2}$ Significantly, whereas the recommendations of the 1910 Flexner Report ${ }^{3}$ pertaining to science-focused premedical and medical curricula reform have been heeded, its implications related to the importance of broader, humanities-focused training for aspiring physicians have gone largely neglected. ${ }^{45}$ However, with the rapid evolution of 20th-century medical technology, educational paradigms must shift to prepare well-rounded clinical and research professionals. ${ }^{467}$ In contemporary healthcare models, which sometimes fail to deliver holistic, patient-centred care, the core tenets of NM have emerged as a means of enhancing clinical care and promoting wellness. 
Scholarly discussion of literature and medicine surfaced in academic literature in the $1970 \mathrm{~s} .{ }^{8}$ By 1995 , one-third of American medical schools had incorporated literature courses into their curricula. ${ }^{9}$ Rita Charon introduced the term narrative medicine into the medical lexicon in 2001. ${ }^{81011} \mathrm{NM}$ continues to evolve as a framework for healthcare ${ }^{12}$ based on Charon's assertion that: 'The effective practice of medicine requires narrative competence, that is, the ability to acknowledge, absorb, interpret, and act on the stories and plights of others. Medicine practiced with narrative competence, called narrative medicine, is proposed as a model for humane and effective medical practice'. ${ }^{11}$ The philosophical and theoretical framework of NM has been reviewed comprehensively by Charon $e t$ al in The Principles and Practice of Narrative Medicine. ${ }^{12}$

The integration of narrative and medicine offers benefits to healthcare providers as well as to patients, since NM draws on literature's unique ability to augment clinical competencies, enhance the moral imagination and foster interpersonal understanding. ${ }^{9}{ }^{13}$ Narrativebased education shows promise for promoting communication, ${ }^{14}$ cultural competence, ${ }^{15}$ empathy ${ }^{16-18}$ and professionalism, ${ }^{19}$ as well as for enhancing vitality and mitigating burnout. ${ }^{20-22}$ To reap the benefits associated with NM, many academic medical institutions have implemented humanities-based educational initiatives into the curricula. ${ }^{23}$ Most NM programmes use a combination of activities, including reading literary narratives, participating in group discussion, engaging in writing exercises, workshopping peer narratives, interviewing patients and creating portfolios.

To date, however, few studies exist that examine and interpret efficacy trends in NM programming as a whole, and the current literature does not assess overarching unmet needs. We report a systematic review of the objectives, contents and evaluation outcomes of existing NM programmes as a means of answering the research question: how effective is the implementation and evaluation of NM programmes in academic medicine and health sciences? We also provide best-practice recommendations and new directions for future narrative-based programming.

Several prior systematic reviews have considered specific aspects of NM. Barber and Moreno-Leguizamon examined whether NM education fosters compassionate care for adult patients and determined that, while the literature suggests that NM may be beneficial in this context, the data were insufficient to draw more robust conclusions. ${ }^{24}$ Chen and Forbes concluded that reflective writing-one component of NM-may enhance empathy in medical students and thus could warrant inclusion in medical school curricula. ${ }^{25}$ Fioretti et al focused on the experience of patients and their caregivers through a lens of NM and indicated a need for clarity and specificity in NM research protocols. ${ }^{26}$ Lasko et al considered narrative interventions within the specific setting of palliative care and recommended the adoption of more consistency across pedagogical frameworks and potential outcomes. ${ }^{27}$
Milota $e t$ al investigated the use of NM as an educational tool for medical students and concluded that, while NM comprises an effective teaching strategy, more research is needed to determine its long-term impact. ${ }^{28}$ Finally, Schoonover et al found that poetry, a component of $\mathrm{NM}$, may increase empathy and reduce burnout among healthcare professionals. ${ }^{29}$

To our knowledge, no systematic review has addressed the overall effectiveness of NM programmes offered to healthcare professionals at varying levels of training and implemented in academic health sciences centres, including medical schools and hospitals. We sought to identify areas in which innovative NM programming may meet existing needs for both clinicians and biomedical researchers at all career stages, including students, residents, clinical and research fellows and faculty. In addition, we identified areas for improvement in the reporting of the design and evaluation of NM programmes.

\section{METHODS}

\section{Criteria for selecting studies for this review}

To be eligible for inclusion in the systematic review, a record had to document NM programming implemented within academic health sciences worldwide. We excluded articles, abstracts, commentary or perspective pieces focused exclusively on NM theory, since an examination of the philosophical and theoretical principles of the NM framework is beyond the scope of this review.

Record eligibility also was contingent on the constituencies to which NM programming was offered. We considered a broad target audience consisting of one or more of the following: 1) graduate medical, dental or health sciences students, including candidates for MD, DMD, PharmD, PhD, MS and MPH degrees; 2) undergraduate or graduate nursing and allied health students; 3) medical, dental, nursing or health sciences trainees, including residents, clinical fellows and research fellows; 4) nurses; 5) allied health professionals; 6) faculty in the medical, dental and health sciences and 7) non-faculty physicians.

A third inclusion criterion involved the educational components of NM training. The history of literature and medicine is grounded in both literary analysis and narrative writing, ${ }^{9}$ although some scholars consider reflective/creative writing to be a relatively recent addition to NM programming. ${ }^{8}$ Nevertheless, writing is a singularly effective means of fostering reflection. ${ }^{30}$ Therefore, we specified that, to be eligible for the systematic review, NM trainings had to include both essential components of NM imbedded in the programmatic core: 1) textual analysis/close reading of published literature (eg, poetry, fiction, creative non-fiction) and 2) creative/reflective writing.

\section{Search methods for identification of studies}

We consulted the Boston University School of Medicine Assistant Director of Library and Information 
Management Education to design a search strategy for the systematic review. Our information sources included five major databases: PubMed, Embase, PsycINFO, ERIC and MedEdPORTAL. PubMed-an online repository of the US National Library of Medicine, National Institutes of Health-is home to over 29 million citations in the realm of biomedical literature. Likewise, Embase indexes significant biomedical literature from across the globe. PsycINFO, the expansive database of the American Psychological Association, focuses on up-to-date behavioural and social science research. ERIC represents the US Department of Education's Institute of Education Sciences online research library. MedEdPORTAL is a database of programme curricula provided by the Association of American Medical Colleges. Strategies were optimised for each database to make the best use of that resource's specific controlled vocabulary or preferred search syntax, and we chose our search terms carefully in order to strike the optimal balance between sensitivity and precision. This is a best practice endorsed by and documented in the Cochrane Handbook for Systematic Reviews for Interventions. ${ }^{31}$ The databases were searched in their entirety through October 2019. A table documenting our electronic search strategy is presented in online supplemental digital appendix 1 .

\section{Data collection and analysis}

We assessed the records identified during the literature search using a two-round, iterative process to reach consensus on eligibility (figure 1), ${ }^{32}$ independently screening the 1569 record abstracts after the removal of duplicates. If an abstract was unavailable, the article text was consulted when possible. To be considered eligible, records had to meet all inclusion criteria. Based on the first round of screening, 164 records qualified for full-text assessment.

During the second screening stage, we read the full texts of records, identifying a further 109 records to exclude due to our discovering on full-text review that they did not meet our established eligibility criteria (figure 1). Following the full-text screening, 61 records qualified for review. ${ }^{15} 22$ 33-89 However, we discovered that several qualifying records addressed identical NM programming efforts at the same institution: that is, 12

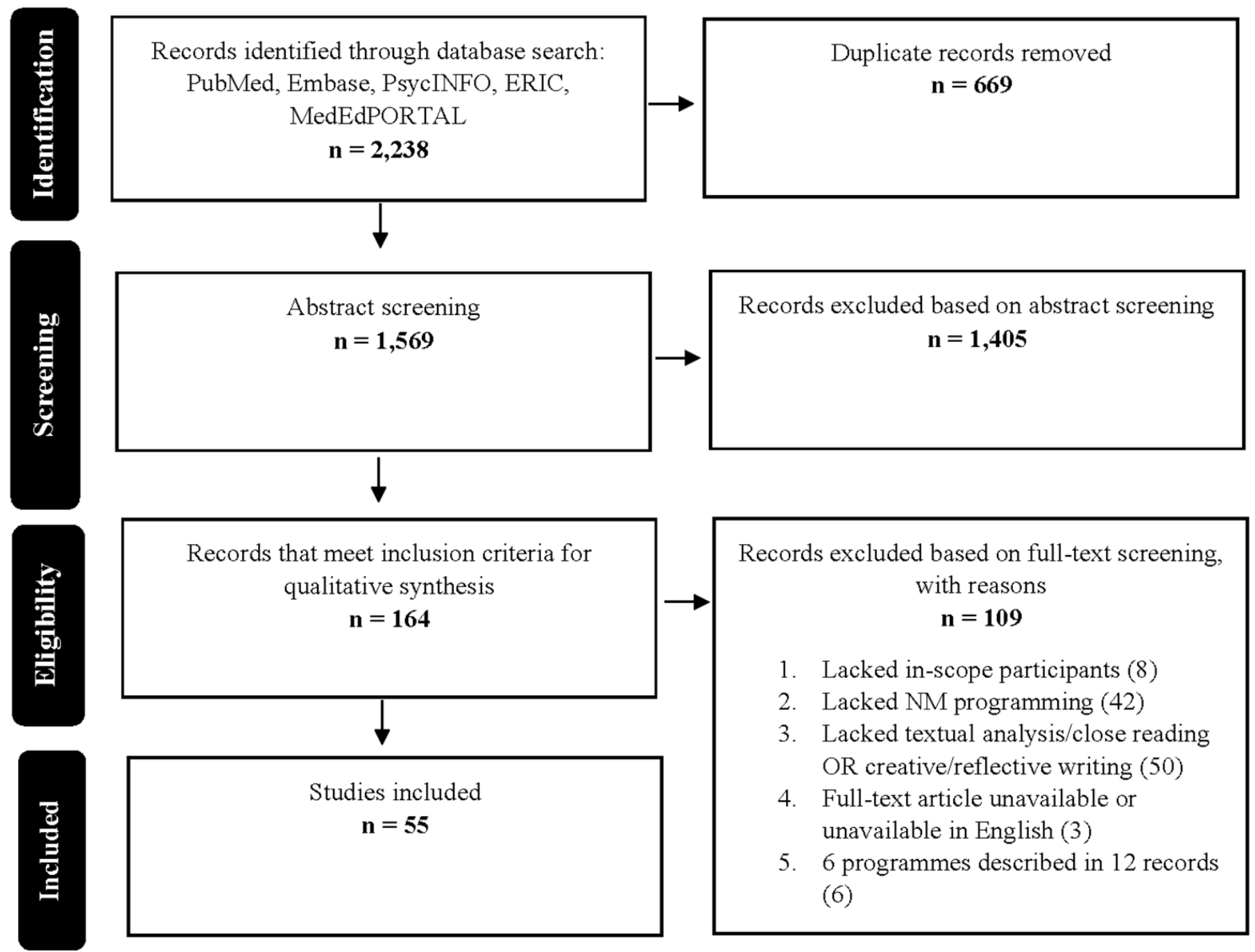

Figure 1 Record search and screening process for narrative medicine (NM) systematic review, through 2019. 
records ${ }^{1522414244-48527084}$ represented 6 programmes. We considered programmes represented by more than one publication type together, thus resulting in 55 unique NM programmes being included in the systematic review.

We performed the data collection independently, analysing the 55 eligible programmes to identify significant information and classifying relevant data for assessing the overall effectiveness of NM in academic medical and health sciences centres. We then crosschecked our results for reliability. Initially, we extracted verbatim data according to date(s) of publication; institution type; geographic location; participant information; programme goals, scope and activities; evaluation methods (table 1); well-described evaluation outcomes (table 2, online supplemental digital appendix 2) and evaluation competencies (figure 2). We coded and synthesised the verbatim data regarding programme context, design, goals and evaluation according to broad themes (online supplemental digital appendix 3).

Since we were particularly interested in identifying the outcomes, as well as the curricular content and goals of NM education, we paid special attention to categorising evaluation methodology used for assessing programme evaluations. We assessed the quality of reporting for all 55 programmes included in the systematic review, classifying programmes according to whether or not they were evaluated, and then differentiating the evaluated programmes according to evaluation design and method. Fourteen $(25.5 \%)$ programmes did not report any evaluation methods. For the remaining $41(74.5 \%)$ programmes, we systematically approached the assessment of programme evaluations according to specific criteria which were applied to all studies in order to ascertain whether the reporting of evaluation methods was adequately or inadequately described.

Quantitative evaluations were deemed 'well described' if they reported the evaluation questions or measures used and the results (including the $\mathrm{N}$ ) to the extent that our study team could interpret the acquisition of NM-related competencies and/or professional growth among programme participants. Qualitative evaluations were deemed 'well described' if they reported the method used to collect qualitative data (eg, content analysis, focus group, open-ended survey) and analysed data from which our study team could interpret whether programme participants had acquired specific NM-related competencies and/or achieved professional growth. Programmes were deemed as 'not well described' if they did not include full details regarding evaluation methods to identify whether the evaluation was conducted in a systematic way.

We stratified programme evaluation based on the type of methods used (qualitative vs quantitative), the thoroughness of the description of the evaluation, including whether the methods and analysis strategy were discussed, and results reported. In regard to evaluation design, programmes were categorised as: 1) crosssectional, including all programmes with postprogramme
Table 1 Descriptive statistics of 55 programmes in narrative medicine systematic review

\begin{tabular}{|c|c|}
\hline Publication year & $\begin{array}{l}2016[2012- \\
2018]^{*}\end{array}$ \\
\hline \multicolumn{2}{|l|}{ Publication type $†$} \\
\hline Article & $36 \ddagger(59.0)$ \\
\hline Abstract & $18 \ddagger(29.5)$ \\
\hline Curriculum & $4 \ddagger(6.6)$ \\
\hline Unpublished theses & $2(3.3)$ \\
\hline Book chapter & $1(1.6)$ \\
\hline \multicolumn{2}{|l|}{ Programme location } \\
\hline USA/Canada & $46(83.7)$ \\
\hline Europe & $5(9.0)$ \\
\hline South/Western Asia & $3(5.5)$ \\
\hline South America & $1(1.8)$ \\
\hline Number of participants & $26.5[12-47.25)$ \\
\hline \multicolumn{2}{|l|}{ Constituency§ } \\
\hline Medical students & $23(41.8)$ \\
\hline Trainees (residents/fellows) & $22(40.0)$ \\
\hline Faculty/Physician non-faculty & $17(30.9)$ \\
\hline $\begin{array}{l}\text { Other staff (eg, administrators, } \\
\text { paramedical personnel, community } \\
\text { workers) }\end{array}$ & $9(16.4)$ \\
\hline Nurses/Nursing students & $9(16.4)$ \\
\hline Other students (eg, graduate students) & $2(3.6)$ \\
\hline \multicolumn{2}{|l|}{ Programme goals§ } \\
\hline \multicolumn{2}{|l|}{ Narrative goals§ } \\
\hline Reflection & $23(41.8)$ \\
\hline Empathy & $22(40.0)$ \\
\hline $\begin{array}{l}\text { Communication/Attentive listening/ } \\
\text { Narrative competence }\end{array}$ & $20(36.4)$ \\
\hline Resilience/Burnout detection/Mitigation & $9(16.4)$ \\
\hline Cultural competence & $3(5.5)$ \\
\hline Wellness & $3(5.5)$ \\
\hline Writing & $3(5.5)$ \\
\hline Narrative skills for pedagogy & $2(3.6)$ \\
\hline \multicolumn{2}{|l|}{ Clinical/Medical skills§ } \\
\hline Clinical competence & $13(23.6)$ \\
\hline Professionalism and vocation & $13(23.6)$ \\
\hline Medical team functioning & $9(16.4)$ \\
\hline Number of sessions & $5([3-11.5]$ \\
\hline Hours in programme & $8(3-17)$ \\
\hline \multicolumn{2}{|l|}{ Programme activities $\ddagger$} \\
\hline $\begin{array}{l}\text { Reading published narratives and writing } \\
\text { reflectively }\end{array}$ & $55(100)$ \\
\hline Group discussion & $46(83.6)$ \\
\hline Sharing/Workshopping writing & $29(52.7)$ \\
\hline $\begin{array}{l}\text { Other (eg, interviews, observations, } \\
\text { portfolios, writing a patient's story, online } \\
\text { forum) }\end{array}$ & $18(32.7)$ \\
\hline
\end{tabular}

Continued 


\begin{tabular}{lr} 
Table 1 Continued & \\
\hline & 2016 [2012- \\
Publication year & 2018]* \\
\hline Programme evaluation methods & \\
Quantitative-well described & $13(23.6)$ \\
Quantitative-incomplete description & $9(16.4)$ \\
Qualitative-well described & $27(49.1)$ \\
Qualitative-incomplete description & $6(10.9)$ \\
None/Not specified & $14(25.5)$
\end{tabular}

Data are $\mathrm{N}$ and interquartile range (Q1-Q3) or percent (\%). ${ }^{*}$ Two studies in the same year counted as one programme; two studies in different years counted as two programmes.

†Percentages are calculated based on 61 records.

$\ddagger$ Programme was represented by more than one publication type (eg, article and curriculum).

$\S$ Responses are not mutually exclusive, so percentages are over $100 \%$.

IFourteen studies used a mixed methods, with both qualitative and quantitative outcomes reported, so percentages are over $100 \%$.

evaluation without a comparator; 2) case-control, using a post-test comparing control and treatment groups; 3) controlled or uncontrolled pre-post test, including all programmes that included both a pretest and a posttest and 4) randomised step-wedge design, including all programmes that used a step-wedge design to examine programme impact on participants randomised to participate at different time points. We were open to including other evaluation designs, but only the four designs discussed here emerged from our analysis of the NM programme included in the systematic review.

In addition to tracking overall evaluation strategies, we used grounded analysis to analyse the extracted data. Hence, programme goals did not necessarily map neatly onto actual outcomes. We recorded the well-described evaluation of specific NM-related competencies according to the following thematic groupings: participant satisfaction, relationship-building, empathy, perspective-taking and reflection, resilience and burnout detection/mitigation, confidence/personal accomplishment, narrative competence, ethical inquiry, pedagogical skills, clinical skills, relevance to work, institutional impact and cultural competence. Attentive listening practices were included in the relationship building and narrative competence thematic groupings.

Patient and public involvement statement

No patients were involved in this study.

\section{RESULTS}

\section{Descriptive statistics}

Table 1 summarises the descriptive statistics of all 55 programmes included in our review. The programmes 
included in our review were documented and disseminated through a variety of media, including articles $(\mathrm{n}=36)$, abstracts $(\mathrm{n}=18)$, MedEdPORTAL curricula $(n=4)$, unpublished theses $(n=2)$ and a book chapter $(n=1)$. Publication dates were from 2005 to 2019, with the median year of publication being 2016 .

NM programming efforts reported in the literature were concentrated in relatively high-resource settings. The bulk of trainings occurred in North America $(n=46$, $83.7 \%)$, followed by Europe $(n=5,9.0 \%)$, Asia $(n=3$, $5.5 \%)$ and South America $(n=1,1.8 \%)$. See online supplemental digital appendix 4 for a map of NM programme locations.

NM programme participants and size varied. Programming was offered for medical students $(\mathrm{n}=23,41.8 \%)$, resident and fellow clinical trainees $(n=22,40.0 \%)$, faculty and non-faculty physicians $(\mathrm{n}=17,30.9 \%)$, nurses and nursing students $(n=9,16.4 \%)$, other staff $(n=9,16.4 \%)$ and other students $(n=2,3.6 \%)$. Some programmes were open to more than one of the above constituencies. Number of participants ranged from 5 to 350 individuals (median 26.5; IQR 12-47.25); for 15 programmes, participant constituency and/or participant numbers were not provided.

The number of sessions offered by NM programme was highly heterogeneous, running the gamut from a single workshop or seminar to as many as 40 half-hour sessions offered over the course of a year. ${ }^{52}$ The median number of sessions offered was 5 (IQR 3-11.5). The number of hours of programming offered was similarly highly variable, ranging from 1 to 60 , with 8 being the median (IQR $3-17)$.

NM programmes specified one or several educational objectives related to both narrative and clinical/medical skills. We grouped programmatic goals involving narrative skills into several categories, including the cultivation of reflection ( $\mathrm{n}=23,41.8 \%)$; empathy ( $\mathrm{n}=22,40.0 \%)$; communication, attentive listening and narrative competence $(n=20,36.4 \%)$; resilience and burnout detection and/or reduction $(\mathrm{n}=9,16.4 \%)$; cultural competence $(n=3,5.5 \%)$; wellness $(n=3,5.5 \%)$; writing $(n=3,5.5 \%)$ and narrative skills for pedagogy $(n=2,3.6 \%)$. Programmatic goals related to clinical/medical skills sought to employ NM to foster clinical competence $(n=13,23.6 \%)$; enhanced sense of professionalism and vocation $(n=13$, $23.6 \%)$ and successful medical team functioning $(n=9$, $16.4 \%)$.

In order to achieve the stated programming goals, NM curricula relied on a combination of activities, including engaging with literary readings and writing reflectively $(\mathrm{n}=55,100 \%)$; group discussion $(\mathrm{n}=46,83.6 \%)$; sharing and/or workshopping participants' writing as a group $(\mathrm{n}=29,52.7 \%)$ and other narrative-based exercises $(\mathrm{n}=18$, $32.7 \%$ ), such as conducting patients' interviews and writing patients' stories, creating portfolios, participating in an online forum and even presenting a play.

\section{NM programme evaluation}

The reporting of NM programme evaluations varied across programme and publication types. Fourteen $(25.5 \%)$ programmes did not report any evaluation activities. For programme reporting quantitative evaluations, we identified 13 as well described and 9 that reported some quantitative methods but were not thoroughly described. As mentioned previously, programmes were deemed as 'not well described' if they did not include full details regarding evaluation methods. See table 2 for explanations for programmes deemed as well described; incomplete quantitative and qualitative programme evaluations are recorded in online supplemental digital appendix 5. For programmes reporting qualitative evaluations, we identified 27 as well described and 6 that were not described thoroughly. Only six NM programmes were deemed as having both quantitative and qualitative evaluation methods that were well described. ${ }^{49515255778485}$

Evaluation designs varied across NM programmes and included the use of cross-sectional designs, casecontrol designs, pre-post designs and randomised stepwedge designs. Of the evaluations we identified as well described, 31 evaluations used a cross-sectional design with a post-test only. Of the evaluations using a crosssectional design, most had only an immediate post-test $(n=29)$, one had an immediate post-test and a long-term post-test $(1.5 \text { years later })^{33}$ and one had a long-term posttest only (1.5 years).$^{90}$ One evaluation did not report the timing of the post-test. ${ }^{52}$ One evaluation used a casecontrol design where participants were randomised into the treatment condition or the control condition. ${ }^{87}$ Of the seven evaluations that used a pre-post design, six did a pre-test and immediate post-test, and one did a pre-test and long-term post-test (1 year). ${ }^{22} 70$ One evaluation used a randomised step-wedge design in which participants were randomised into two groups, and the groups participated in the programme at different times. ${ }^{41}{ }^{42}$ Post-tests of programme participants were compared with pre-tests of those who had not yet participated in the programme.

Overall, the quantitative and qualitative evaluations demonstrated that NM programming can have a variety of positive impacts on healthcare providers, showing evidence for modest gains in a variety of competencies, including relationship-building, empathy, perspectivetaking/reflection, resilience and burnout mitigation/ detection, confidence/personal accomplishment, narrative competence, ethical inquiry, pedagogical skills and clinical skills (table 2 and figure 2). In addition to evaluating the impact of the programme on participants, many evaluation strategies focused on evaluating participants' satisfaction with the programme. NM satisfaction scores were reported to be high, with the combined per cent agree or strongly agree to the satisfaction measures as $87.9 \%$ (our calculation). However, satisfaction outcomes were not necessarily indicative of subsequent changes in the behaviour or experiences of health sciences professionals who engaged in the programming. 
Table 2 Quantitative and qualitative well-described evaluations of narrative medicine programme in systematic review*

2A. Quantitative evaluations-well described

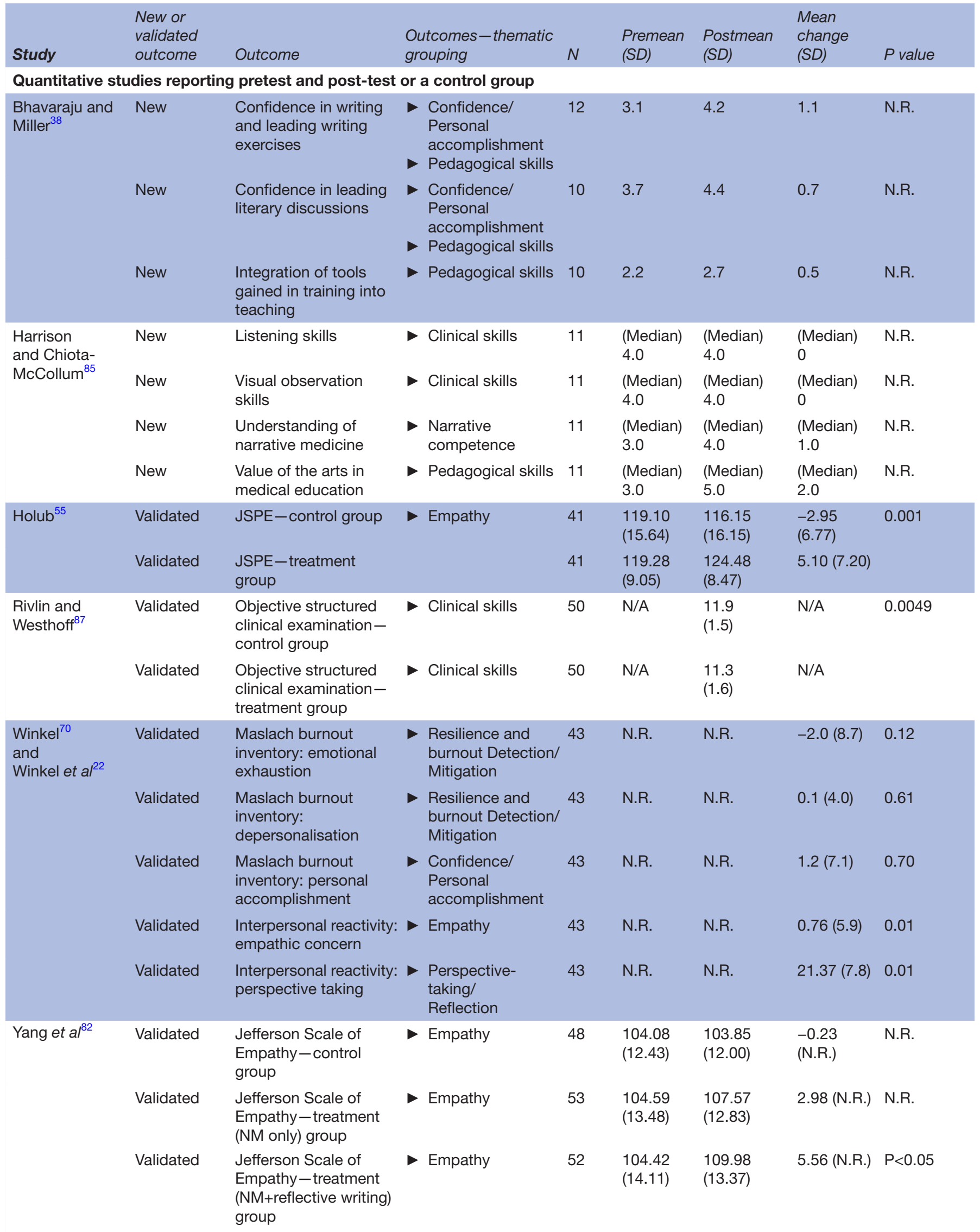


Table 2 Continued

Quantitative studies using a cross-sectional design with a post-test only

\begin{tabular}{|c|c|c|c|c|c|}
\hline Study & $\begin{array}{l}\text { New or } \\
\text { validated } \\
\text { outcome }\end{array}$ & Outcome & $\begin{array}{l}\text { Outcomes-thematic } \\
\text { grouping }\end{array}$ & $N$ & $\begin{array}{l}\text { Postmean } \\
\text { (SD) }\end{array}$ \\
\hline \multirow[t]{3}{*}{ Goupy et $a l^{51}$} & New & Interest of topic & Satisfaction & 41 & $1.84(0.82)$ \\
\hline & New & Satisfaction with choice of theme & Satisfaction & 41 & $2.13(0.72)$ \\
\hline & New & Satisfaction of discussion related to theme & Satisfaction & 41 & $2.30(0.62)$ \\
\hline \multirow{3}{*}{$\begin{array}{l}\text { Whitesides et } \\
a l^{89}\end{array}$} & New & Quality of sessions & Satisfaction & 44 & 4.5 \\
\hline & New & Usefulness of writing component & Satisfaction & 44 & 3.9 \\
\hline & New & Usefulness of the group discussion & Satisfaction & 44 & 4.5 \\
\hline Study & $\begin{array}{l}\text { New or } \\
\text { validated } \\
\text { outcome }\end{array}$ & Outcome & $\begin{array}{l}\text { Outcomes-thematic } \\
\text { grouping }\end{array}$ & $N$ & $\begin{array}{l}\% \\
\text { agreement } \\
\text { with } \\
\text { outcome }\end{array}$ \\
\hline \multirow{3}{*}{$\begin{array}{l}\text { Gowda et } a l^{84} \\
\text { and } \\
\text { Gowda et } a l^{52}\end{array}$} & New & Participant would recommend training & - Satisfaction & 50 & 94 \\
\hline & New & Participant would continue participating & - Satisfaction & 50 & 74 \\
\hline & New & $\begin{array}{l}\text { Programme's ability to facilitate interprofessional } \\
\text { dialogue }\end{array}$ & - Relationship-building & 50 & 90 \\
\hline \multirow[t]{2}{*}{ Goodrich et $a l^{49}$} & New & Usefulness of the training & - Satisfaction & 48 & 79 \\
\hline & New & Interest of the training & - Satisfaction & 48 & 88 \\
\hline \multirow[t]{2}{*}{ Hinyard et $a l^{77}$} & New & $\begin{array}{l}\text { Writing about own experiences helped develop } \\
\text { communication skills }\end{array}$ & - Relationship-building & 24 & 80 \\
\hline & New & $\begin{array}{l}\text { Listening to stories helped develop communication } \\
\text { skills }\end{array}$ & - Relationship-building & 24 & 88 \\
\hline \multirow[t]{2}{*}{ Moss et al ${ }^{63}$} & New & Satisfaction of training & - Satisfaction & 27 & 99 \\
\hline & New & Relevance of training to work & Relevance to work & 27 & 97 \\
\hline \multirow[t]{3}{*}{ Walker et al ${ }^{69}$} & New & Total satisfaction with course & - Satisfaction & 20 & 89 \\
\hline & New & Appropriateness of activities & - Satisfaction & 32 & 94 \\
\hline & New & Overall experience with instructors & - Satisfaction & 32 & 97 \\
\hline
\end{tabular}

2B. Qualitative evaluations-well described $\dagger$

\begin{tabular}{|c|c|c|c|c|}
\hline Study & Design & Timing & Methods & Outcome improved-thematic grouping \\
\hline Adamson et $\mathrm{al}^{74}$ & $\begin{array}{l}\text { Pretest and } \\
\text { post-test }\end{array}$ & $\begin{array}{l}\text { Pretest, immediate } \\
\text { post-test }\end{array}$ & Interviews & $\begin{array}{l}\text { Empathy } \\
\text { Relationship-building } \\
\text { Confidence/Personal accomplishment }\end{array}$ \\
\hline $\begin{array}{l}\text { Balmer and } \\
\text { Richards }^{37}\end{array}$ & Post-test & Immediate & $\begin{array}{l}\text { Ethnography, content } \\
\text { analysis, interviews }\end{array}$ & $\begin{array}{l}\text { Institutional impact } \\
\text { Pedagogical skills } \\
\text { Relationship-building } \\
\text { Perspective-taking/Reflection }\end{array}$ \\
\hline Birigwa et $\left.a\right|^{39}$ & Post-test & Immediate & Surveys & $\begin{array}{l}\text { Relationship-building } \\
\text { Resilience and burnout detection/Mitigation } \\
\text { - Perspective-taking/Reflection }\end{array}$ \\
\hline Bobb $^{40}$ & Post-test & Immediate & $\begin{array}{l}\text { Ethnography, } \\
\text { interviews }\end{array}$ & $\begin{array}{l}\text { Perspective-taking/Reflection } \\
\text { Relationship-building } \\
\text { Confidence/Personal accomplishment }\end{array}$ \\
\hline $\begin{array}{l}\text { Brigley and } \\
\text { Jasper }\end{array}$ & Post-test & Immediate & $\begin{array}{l}\text { Observation, focus } \\
\text { groups, interviews }\end{array}$ & $\begin{array}{l}\text { Relationship-building } \\
\text { Perspective-taking/Reflection }\end{array}$ \\
\hline $\begin{array}{l}\text { Chretien et } a{ }^{44} \\
\text { and } \\
\text { Chretien et } a l^{45}\end{array}$ & Post-test & Immediate & $\begin{array}{l}\text { Focus groups, patient } \\
\text { interviews }\end{array}$ & $\begin{array}{l}\text { Narrative competence } \\
\text { Relationship-building } \\
\text { Satisfaction }\end{array}$ \\
\hline
\end{tabular}


Table 2 Continued

\begin{tabular}{|c|c|c|c|c|}
\hline $\begin{array}{l}\text { Cunningham } \\
\text { et } a l^{76}\end{array}$ & Post-test & Immediate & $\begin{array}{l}\text { Content analysis of } \\
\text { essays }\end{array}$ & $\begin{array}{l}\text { Empathy } \\
\text { Perspective-taking/Reflection }\end{array}$ \\
\hline $\begin{array}{l}\text { DasGupta et } \\
\text { al }^{46} \\
\text { and } \\
\text { DasGupta }^{15}\end{array}$ & Post-test & Immediate & $\begin{array}{l}\text { Focus groups, } \\
\text { resident evaluations }\end{array}$ & $\begin{array}{l}\text { Cultural competence } \\
\text { Relationship-building } \\
\text { Empathy }\end{array}$ \\
\hline Goodrich et a ${ }^{49}$ & Post-test & Immediate & $\begin{array}{l}\text { Focus group; } \\
\text { programme } \\
\text { evaluation survey }\end{array}$ & $\begin{array}{l}\text { Empathy } \\
\text { Ethical inquiry } \\
\text { Narrative competence } \\
\text { Relationship-building }\end{array}$ \\
\hline Gordon $^{50}$ & Post-test & Immediate & $\begin{array}{l}\text { Content analysis of } \\
\text { essays }\end{array}$ & - Resilience and burnout detection/Mitigation \\
\hline Goupy et $a l^{51}$ & Post-test & Immediate & Open-ended survey & - Satisfaction \\
\hline $\begin{array}{l}\text { Gowda et a }{ }^{52} \\
\text { and } \\
\text { Gowda et } a l^{84}\end{array}$ & $\begin{array}{l}\text { Pretest, } \\
\text { midpoint- } \\
\text { test and } \\
\text { post-test }\end{array}$ & $\begin{array}{l}\text { Pretest, midpoint-test, } \\
\text { immediate post-test }\end{array}$ & $\begin{array}{l}\text { Observational notes, } \\
\text { interviews, survey }\end{array}$ & $\begin{array}{l}\text { Perspective-taking/Reflection } \\
\text { - Relationship-building } \\
\text { Satisfaction }\end{array}$ \\
\hline Hinyard et $a l^{77}$ & Post-test & Immediate & Open-ended survey & $\begin{array}{l}\text { Empathy } \\
\text { Perspective-taking/Reflection } \\
\text { - Relationship-building }\end{array}$ \\
\hline Holub $^{55}$ & Post-test & Immediate & Focus groups & - Empathy \\
\hline $\begin{array}{l}\text { Kennedy and } \\
\text { Sgro }^{58}\end{array}$ & Post-test & Immediate & Open-ended survey & - Satisfaction \\
\hline Murrinson $^{64}$ & Post-test & Immediate & $\begin{array}{l}\text { Content analysis of } \\
\text { responses }\end{array}$ & $\begin{array}{l}\text { Empathy } \\
\text { Ethical inquiry } \\
\text { Perspective-taking/Reflection }\end{array}$ \\
\hline Spike ${ }^{91}$ & Post-test & Immediate & Open-ended survey & - Satisfaction \\
\hline Walker et a/ ${ }^{69}$ & Post-test & Immediate & Open-ended survey & - Satisfaction \\
\hline Wesley et $a l^{81}$ & Post-test & Immediate & Open-ended survey & $\begin{array}{l}\text { Empathy } \\
\text { Relationship-building } \\
\text { - Resilience and burnout detection/Mitigation }\end{array}$ \\
\hline Winkel et $a l^{71}$ & Post-test & Immediate & Questionnaire & - Satisfaction \\
\hline $\begin{array}{l}\text { Wohlmann and } \\
\text { Halstein }^{72}\end{array}$ & Post-test & Immediate & Open-ended survey & - Satisfaction \\
\hline Zohouri et $a l^{73}$ & Post-test & Immediate & $\begin{array}{l}\text { Content analysis of } \\
\text { essays }\end{array}$ & $\begin{array}{l}\text { Empathy } \\
\text { Relationship-building } \\
\text { Perspective-taking/Reflection }\end{array}$ \\
\hline
\end{tabular}

*All quantitative evaluations-well-described report evaluation at the end of the programme except for Winkel et al and Winkel. ${ }^{22} 70$ †See online supplementary appendix 2 for outcomes/findings.

N/A, not available; N.R., not reported.

Of quantitative programmes deemed as well described, six reported high satisfaction 49515263698489 while modest and positive but not statistically significant impacts were reported on: pedagogical skills $(n=2),{ }^{88}$ relevance to professional work $(\mathrm{n}=1),{ }^{63}$ resilience and burnout detection/mitigation $(n=1)^{2270}$ and confidence/increased sense of personal accomplishment $(n=2) .^{22} 3870$ Programmes that reported statistically significant programmatic 
impacts examined increased empathy $(\mathrm{n}=3), 22557082$ and increased perspective-taking/reflection $(n=1) .^{22} 70$

Of qualitative programmes deemed as well described, 10 reported high satisfaction, ${ }^{4} 424445515258697172848591$ while positive impacts were reported on: relationship-

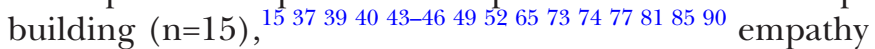
(n=10), ${ }^{15} 46495564737476778190$ perspective-taking/reflection $(\mathrm{n}=10),{ }^{3739404352647376778485}$ resilience and burnout detection/mitigation $(n=4),{ }^{39} 508190$ narrative competence $(n=3),{ }^{41} 42444549$ confidence/personal accomplishment $(n=3), 334074$ ethical inquiry $(n=2),{ }^{49} 64$ relevance to work $(n=1),{ }^{33}$ pedagogical skills $(n=1),{ }^{37}$ cultural competence $(n=1),{ }^{15} 46$ and institutional impact $(n=1){ }^{37}$

We observed that the stated goals of NM programmes were not always reflective of the reported evaluation outcomes. Programmes identified a variety of goals, but a striking number did not report actual evaluation results $(\mathrm{n}=14)^{343553545659-627579808392}$ or only discussed general participant satisfaction $(n=7) .{ }^{51586971728991}$ We found the evaluation methods and outcomes of many programmes to be insufficiently developed or described.

\section{DISCUSSION}

Our review of $55 \mathrm{NM}$ programmes demonstrated modest but positive varied benefits related to narrative-based education for health science professionals, reflective of the remarkable diversity of the trainings implemented. From a geographical perspective, the bulk of programmes took place in North America, followed by Europe. Audiences varied, but the highest concentration of programmes were targeted at medical students, followed by trainees (residents and fellows) and then faculty and non-faculty physicians. Programme goals encompassed a range of narrative and clinical skills. Programme activities tended to concentrate on reading and discussion, as well as on reflective writing exercises.

Most evaluation designs used a cross-sectional, posttest only evaluation, which did not allow evaluators to understand the relative impact of the programme. Only nine programmes compared participants before and after the NM training, using either a pre-post or stepwedge design. Only four programmes evaluated the long-term impact of the training, with postprogramme evaluations conducted between 1 month and 1.5 years after programme completion. The majority of programming was evaluated by qualitative, quantitative or mixed methods for satisfaction and/or efficacy. The qualitative studies highlighted a more nuanced breadth of outcomes regarding personal and professional benefits for participants in NM programmes. Despite an emphasis on the value of writing, no programmes used an evaluation deemed to be well described to assess gains in writing competence/confidence, and a surprisingly high number $(\mathrm{n}=14,25.5 \%)$ of $\mathrm{NM}$ programmes provided no details regarding evaluation design or methodology.

Whereas previous systematic reviews have concluded that NM education may be beneficial in contributing to compassionate care, ${ }^{24}$ enhanced empathy ${ }^{25} 29$ and effective teaching, ${ }^{28}$ our research builds on the current literature to reveal a broad range of NM benefits. Our findings demonstrate that NM has shown potential for enhancing communication and team-building skills, encouraging perspective-taking and reflection, promoting empathic behaviour, detecting/mitigating burnout, cultivating narrative competence, augmenting pedagogical and clinical skills, and fostering ethical inquiry.

Based on our analysis and interpretation of the programmes reviewed, we recommend considering the inclusion of narrative-based education in curricula for medical/health sciences students, trainees and faculty. We also suggest several best practices and new directions for future NM programming efforts as a means of increasing efficacy and providing broader accessibility.

\section{Recommended best practices and future directions for NM Enhanced programme evaluation methods}

Our research has noted that a substantial number of NM programmes did not report any evaluation activities, while others only evaluated general participant satisfaction. Furthermore, in programmes that were evaluated, evaluation design was highly variable, with the majority lacking assessment of long-term impact. Without carefully evaluating the short-term and long-term outcomes of educational programming for gaining particular skills and competencies, it is difficult to continue assessing accurately whether NM programming addresses the unique needs of health sciences professionals in academic medicine and health sciences. Given the intense time constraints of the constituency, we submit that programme evaluation is critical to ensure that time spent in an NM programme is used effectively.

Quantifying the long-term impact of NM objectives, such as fostering empathy and ethical decision-making, is challenging-and certainly complicates the integration of NM training into continuing medical education curricula. $^{93}$ Nevertheless, education experts contend that medical ethics and humanities training, including narrative-based reasoning, is fundamental to the professional development of healthcare practitioners. ${ }^{94}$ Ensuring the integration of relevant NM programming into educational curricula for the next generation of health sciences professionals requires strategic planning, thorough evaluation and ongoing analysis. We have constructed a basic checklist for developing, implementing, evaluating and disseminating an NM training, regardless of individual programme focus (online supplemental digital appendix 6).

\section{Focus on narrative writing skills}

Narrative writing has the potential to leverage storytelling as an aspect of personal and professional growth. The literature supports that faculty writing groups and workshops can promote publications and presentations, ${ }^{95-97}$ improve writing skills ${ }^{96}$ and bolster confidence in writing. ${ }^{96} 9799$ However, we identified only one NM 
intervention that reported the development of writing skills as a programme goal, ${ }^{34}$ rather than the use of writing as a means towards achieving other stated outcomes, such as the cultivation of reflection or empathy skills. While no programme reported evaluation of writing-related competencies in a manner deemed well described, participants did report valuing the opportunity to improve their writing skills ${ }^{58}$ and augment self-efficacy in writing/ leading writing exercises. ${ }^{38}$

NM programming that includes training in writing competencies and self-efficacy represents an innovative educational model for accomplishing both the traditional goals of NM-for example, empathy, communication, professionalism, resilience-and the additional outcome of fostering writing competencies for academic growth. We recommend expanding future NM programme objectives to include the development of enhanced writing skills and self-efficacy related to the writing process as measurable learning outcomes. Such a goal may be accomplished through a blend of expert-led instruction in literary theory, close reading of published literary texts and workshopping of peer narratives, with the goal of coaching faculty to generate perspective pieces, advocacy narratives, creative writing projects and educational texts for submission to peer-reviewed journals.

\section{NM for scientists}

To date, a dearth of research exists regarding the occurrence and effectiveness of NM programming for scientists, and we submit that this knowledge gap should be addressed by the implementation and evaluation of narrative-based education for this constituency. The NM programmes analysed in the current review were overwhelmingly geared towards clinical professionals, including physicians, nurses, clinical fellows, residents, medical students and clinically-oriented staff. However, many of the programmes' positive outcomes may be equally valuable for research faculty, postdoctoral fellows and graduate students in the health sciences, who may benefit from narrative-based training to enhance communication and relationship-building skills, writing and teaching competencies, cross-cultural awareness, understanding of ethical inquiry and behaviour, crossdisciplinary understanding, and professional identity formation.

While much attention has been given to clinician stress and burnout, NM also may prove beneficial for researchers navigating the stressors of a historically challenging funding climate. The inclusion of both clinical and research-focused professionals in NM programming has potential to foster interdisciplinary understanding, build affinity and offer collaborative opportunities to groups who tend to operate in silos.

\section{NM for detecting and mitigating burnout}

Given current concerns surrounding stress and burnout among professionals in medicine and health sciences, ${ }^{100-105}$ a need exists to identify and implement sustainable programming for cultivating resilience. Five well-described programmes evaluated the impact of NM education on resilience and burnout detection and/or mitigation. ${ }^{22} 3950708190$ While in one case quantitative evaluations of burnout after NM training (incomplete description) did not demonstrate statistical significance, ${ }^{71}$ other programmes suggested positive results regarding the use of NM for burnout identification and reduction.

Although NM programmes offer a promising initial step towards employing narrative-based education for resilience, additional research is needed to demonstrate the potential impact of NM education on physician and scientist wellness, particularly in specialties and contexts with high burnout rates. While preliminary studies have explored how narrative practice and reflective practice may constitute effective interventions for frontline medical responders working in the burnout-prone context of international humanitarian frameworks, ${ }^{106} 107$ reports on research, development and implementation of NM programming for such constituencies are scarce. Therefore, we suggest further development and evaluation of narrative-based education focused on burnout detection and mitigation - with the potential for adapting successful NM programming to burnout-prone healthcare contexts beyond academic medicine, including among humanitarian and military frontline medical providers.

\section{NM for cultural competence}

Several programmes included in our review expressed increased cultural competence, communication and/or sensitivity as primary or secondary goals. ${ }^{15} 46586466$ Given the power of literature for developing empathy ${ }^{108}$ and expanding the moral imagination, ${ }^{9}$ it is probable that NM programming could serve a unique role in fostering cultural sensitivity and illuminating implicit bias, particularly since literature has been posited as a powerful vehicle for exploring themes of racial justice within medicine. ${ }^{109}$ We therefore recommend additional research into NM education as a vehicle for promoting cultural competence, ${ }^{110}$ which might be accomplished in a variety of ways, including by imbedding narrative-based learning modules into unconscious bias trainings already taking place within academic health sciences.

\section{NM for low-resource settings}

From a global perspective, NM programming efforts to date have been based primarily in high-resourced medical areas. There are opportunities for educational partnerships among institutions located in disparate geographic and socioeconomic settings both within the USA and abroad. Certainly the appearance of NM programming worldwide demonstrates a burgeoning global interest in the field, with $20 \% \quad(n=11)$ of training having been implemented outside the USA in recent years: Nepal in $2009,{ }^{67}$ the UK in $2010,{ }^{43}$ Canada and Chile in 2012, ${ }^{41,42,69}$ France in $2013,{ }^{51}$ Italy in $2014,{ }^{65}$ Germany and Portugal in $2016,{ }^{61}{ }^{72}$ Iran in $2017,{ }^{73}$ and Canada and China in $2018 .^{74,82}$ 
The increasing interest in NM education on a global level, including in some low-resource settings, offers potential for development of scalable curricula that can be shared with resource-limited locations where humanities and medicine training curricula may still be scarce, as was reported to be the case in Nepal. ${ }^{67}$ One potential strategy for implementing NM programming in lowresource settings would be to create curricula for blended online and in-person educational modules. This type of programme could leverage videoconferencing technology to connect first-time course implementers with more experienced facilitators, possibly located in higherresource settings, allowing for peer mentoring using NM as both a healthcare framework and an educational tool.

\section{Limitations}

We acknowledge several limitations to our systematic review. Because the scope of this review was focused on the implementation, components and evaluation of NM programmes, as opposed to the theory and philosophy underpinning NM as a conceptual framework for health, we did not extend our search to include humanities-based journals such as Narrative, PMLA and Poetics Today. Furthermore, we did not systematically analyse the philosophical and theoretical orientations of the specific NM programmes surveyed, and it is possible that doing so may have helped to inform our understanding of choices made in terms of programme components and evaluations.

Since the conceptual framework of NM generated in the USA-although the framework is firmly rooted in an older, global tradition of medical and health humanitiesto some extent the vocabulary and definitions associated with NM programming tends to reflect a particularly American viewpoint on academic health sciences education. We attempted to render our analysis of the records more globally inclusive by including programmes that did not specifically employ NM language (some refer instead to 'storytelling', 'medical humanities', etc), but still met our stated selection criteria.

Our results are inevitably subject to potential publication bias, since programmes with positive results are more likely to have been submitted and selected for publication. While the NM records made little mention of negative or neutral aspects of NM programming, such factors undoubtedly exist, including institutional funding limitations, faculty unfamiliarity with NM theory and participant time constraints. Furthermore, we noted the stated definition of NM to be inconsistent even within publications/ programmes that met our inclusion criteria, a factor which may have led to some lack of consistency within reports of programme objectives, evaluations, and outcomes.

Eighteen qualifying records were abstracts, which by nature provide far less information than articles, curricula, unpublished theses or book chapters. Additionally, we recognise the inevitable complexities and potential pitfalls of synthesising mixed data from educational evaluations that have used varying methodologies. ${ }^{111}$ In particular, given our reliance on qualitative analysis when synthesising the data, there is inevitably some element of subjectivity involved in data reporting and interpretation. Although we have made a good faith effort in our work, we do recognise that a degree of subjectivity is inevitable. In a discursive way, our review also raises questions regarding the need for further study on best practices for performing quantitative studies of qualitative endeavours such as NM programming and other social science variables.

Finally, while we have provided discussion regarding ways in which the general thematic schema of NM programme effectiveness may be transferable to future educational efforts, nevertheless we are aware that it is unclear how transferable the results of any specific programme may be, since many dimensions influence the impact of NM programming, including the unique participants, facilitator, curriculum and frequency/duration of sessions. To a great extent, however, this challenge supersedes NM and remains ubiquitous to medical and health sciences education as a whole.

\section{CONCLUSION}

Despite being a relative newcomer to contemporary medical education, NM programming already has resulted in a range of positive outcomes for health sciences professionals, including enhancing narrative competence, communication and empathy; detecting and mitigating burnout; fostering reflection with regard to professional identity formation; promoting team-building and facilitating teaching competencies. Although a plethora of positive outcomes may stem from NM, its foundational competencies-as is implied by the very word humanities, from which NM draws its essential core-involve an ongoing exploration of what it means to understand reality and pursue human good, as this relates to our interactions with ourselves, others and the world.

There are doubtless institutional barriers to overcome in implementing NM programming, including obtaining sufficient institutional or outside funding, augmenting conceptual understanding with medical education committees regarding the positive outcomes of narrativebased education and providing protected time for faculty/ trainee participation in NM curricula. Nevertheless, NM education shows promise for addressing some of the most pressing concerns for today's health sciences professionals, including high suicide rates as well as depression and burnout, compounded with declining research funding, shorter patient visit times, mounting paperwork and decreased job satisfaction. Such challenges necessitate innovative solutions-and NM may prove to be a highly resource-effective solution.

\section{Implications for research}

We advise that NM programming best practices and future directions should include the use of robust evaluation mechanisms; inclusion of writing training as an additional learning outcome; and the development and implementation of NM for researchers, burnout-prone 
providers/contexts, cultural competence trainings and low-resource settings. We hope our systematic review helps to further the integration of narrative-based education into curricula at all levels in academic health sciences with a view towards nurturing resilient, reflective and emotionally intelligent professionals who, in turn, will provide better patient care, health sciences education, research and public health.

Acknowledgements The authors would like to thank Ziva Averbuch for her help reviewing a foreign-language article. The authors also would like to acknowledge that Robina M. Bhasin, EdM, recently has accepted a role as Director of Talent Development, Penn Foster Education Group, Boston, Massachusetts, USA.

Contributors The authors have made substantial contributions to the manuscript materials as follows: CDR engaging in the conceptualisation and design of the work - and in the acquisition, analysis and interpretation of data. Drafting and critically revising the manuscript in regard to significant intellectual content. Giving final approval to the version of the work submitted for publication. Agreeing to be held accountable for all aspects of the work, including ensuring that any inquiries related to the accuracy and/or integrity of the work are appropriately investigated and resolved. EC engaging in the conceptualisation and design of the work-and in the acquisition, analysis and interpretation of data. Drafting and critically revising the manuscript in regard to significant intellectual content. Giving final approval to the version of the work submitted for publication. Agreeing to be held accountable for all aspects of the work, including ensuring that any inquiries related to the accuracy and/or integrity of the work are appropriately investigated and resolved. JCP engaging in the conceptualisation and design of the work-and in the acquisition, analysis and interpretation of data. Drafting and critically revising the manuscript in regard to significant intellectual content. Giving final approval to the version of the work submitted for publication. Agreeing to be held accountable for all aspects of the work, including ensuring that any inquiries related to the accuracy and/or integrity of the work are appropriately investigated and resolved. LT engaging in the conceptualisation and design of the work-and in the analysis and interpretation of data. Critically revising the manuscript in regard to significant intellectual content. Giving final approval to the version of the work submitted for publication. Agreeing to be held accountable for all aspects of the work, including ensuring that any inquiries related to the accuracy and/or integrity of the work are appropriately investigated and resolved. DBF engaging in the conceptualisation and design of the work-and in the acquisition and analysis of data. Critically revising the manuscript in regard to significant intellectual content. Giving final approval to the version of the work submitted for publication. Agreeing to be held accountable for all aspects of the work, including ensuring that any inquiries related to the accuracy and/or integrity of the work are appropriately investigated and resolved. SLW engaging in the interpretation of data. Critically revising the manuscript in regard to significant intellectual content. Giving final approval to the version of the work submitted for publication. Agreeing to be held accountable for all aspects of the work, including ensuring that any inquiries related to the accuracy and/or integrity of the work are appropriately investigated and resolved. RMB engaging in the interpretation of data. Critically revising the manuscript in regard to significant intellectual content. Giving final approval to the version of the work submitted for publication. Agreeing to be held accountable for all aspects of the work, including ensuring that any inquiries related to the accuracy and/or integrity of the work are appropriately investigated and resolved. LBD engaging in the interpretation of data. Critically revising the manuscript in regard to significant intellectual content. Giving final approval to the version of the work submitted for publication. Agreeing to be held accountable for all aspects of the work, including ensuring that any inquiries related to the accuracy and/or integrity of the work are appropriately investigated and resolved. EB engaging in the conceptualisation and design of the work-and analysis and interpretation of data. Critically revising the manuscript in regard to significant intellectual content. Giving final approval to the version of the work submitted for publication. Agreeing to be held accountable for all aspects of the work, including ensuring that any inquiries related to the accuracy and/or integrity of the work are appropriately investigated and resolved.

Funding This research was supported by the: National Institutes of Health (NIH) and the Food and Drug Administration (FDA) Center for Tobacco Products (CTP) Award Numbers P50HL120163 and U54HL120163-06. NIH/NHLBI Award Numbers R01HL141434, 5R01HL128914, R01HL126136 and R01HL092577. American Heart Association (AHA) Award Numbers 18SFRN34110082 and 18SFRN34150007. Robert Wood Johnson Foundation Grant 74624: 'Studying mHealth technologies to help people improve their health and share their health information in real time with health care providers'. Columbia University 2018-2019 Narrative Medicine Fellowship: 'Peer-led Narrative Medicine Workshops for First and Second Year Medical Students' (US\$2000 awarded to BU medical student John Carlo Pasco, coauthor).

Map disclaimer The depiction of boundaries on this map does not imply the expression of any opinion whatsoever on the part of BMJ (or any member of its group) concerning the legal status of any country, territory, jurisdiction or area or of its authorities. This map is provided without any warranty of any kind, either express or implied.

Competing interests None declared.

Patient consent for publication Not required.

Provenance and peer review Not commissioned; externally peer reviewed.

Data availability statement All data relevant to the study are included in the article or uploaded as supplementary information.

Open access This is an open access article distributed in accordance with the Creative Commons Attribution Non Commercial (CC BY-NC 4.0) license, which permits others to distribute, remix, adapt, build upon this work non-commercially, and license their derivative works on different terms, provided the original work is properly cited, appropriate credit is given, any changes made indicated, and the use is non-commercial. See: http://creativecommons.org/licenses/by-nc/4.0/.

ORCID iD

Christy DiFrances Remein http://orcid.org/0000-0002-0130-0326

\section{REFERENCES}

1 Bouterse J, Karstens B. A diversity of divisions: tracing the history of the demarcation between the sciences and the humanities. Isis 2015;106:341-52

2 Weisz G. The emergence of medical specialization in the nineteenth century. Bull Hist Med 2003;77:536-74.

3 Flexner A, Pritchett HS. Medical education in the United States and Canada; a report to the carnegie foundation for the advancement of teaching. New York City, 1910.

4 Marchalik D. The return to Literature-Making doctors matter in the new era of medicine. Acad Med 2017;92:1665-7.

5 Riggs G. Commentary: are we ready to embrace the rest of the Flexner report? Acad Med 2010;85:1669-71.

6 Johnston SC. Anticipating and training the physician of the future: the importance of caring in an age of artificial intelligence. Acad Med 2018;93.

7 Bosch G, Casadevall A. Graduate biomedical science education needs a new philosophy. MBio 2017;8.

8 Jones AH. Why teach literature and medicine? answers from three decades. J Med Humanit 2013;34:415-28.

9 Hunter KM, Charon R, Coulehan JL. The study of literature in medical education. Acad Med 1995;70:787-94.

10 Charon R. Narrative medicine: form, function, and ethics. Ann Intern Med 2001;134:83-7.

11 Charon R. Narrative medicine: a model for empathy, reflection, profession, and trust. JAMA 2001;286:1897-902.

12 Charon R, DasGupta S, Hermann N, et al. The Principles and Practice of Narrative Medicine. New York, NY: Oxford University Press, 2017.

13 Charon Ret al. Literature and medicine: contributions to clinical practice. Ann Intern Med 1995:122:599-606.

14 Tsai S-L, Ho M-J. Can narrative medicine training improve OSCE performance? Med Educ 2012;46:1112-3.

15 DasGupta S. How to catch the story but not fall down: reading our way to more culturally appropriate care. Virtual Mentor 2006;8:315-8.

16 Deen SR, Mangurian C, Cabaniss DL. Points of contact: using firstperson narratives to help foster empathy in psychiatric residents. Academic Psychiatry 2010;34:438-41.

17 Chen P-J, Huang C-D, Yeh S-J. Impact of a narrative medicine programme on healthcare providers' empathy scores over time. BMC Med Educ 2017;17.

18 DasGupta S, Charon R. Personal illness narratives: using reflective writing to teach empathy. Acad Med 2004;79:351-6.

19 Miller E, Balmer D, Hermann N, et al. Sounding narrative medicine: studying students' professional identity development at Columbia University College of physicians and surgeons. Acad Med 2014;89:335-42. 
20 Wald HS, Haramati A, Bachner YG, et al. Promoting resiliency for interprofessional faculty and senior medical students: outcomes of a workshop using Mind-body medicine and interactive reflective writing. Med Teach 2016;38:525-8.

21 Veno M, Silk H, Savageau JA, et al. Evaluating one strategy for including reflection in medical education and practice. Fam Med 2016;48:300-4.

22 Winkel AF, Feldman N, Moss $\mathrm{H}$, et al. Narrative medicine workshops for obstetrics and gynecology residents and association with burnout measures. Obstet Gynecol 2016;128:27S-33.

23 National Academies of Sciences E, Medicine. The Integration of the Humanities and Arts with Sciences, Engineering, and Medicine in Higher Education: Branches from the Same Tree. Washington, DC: The National Academies Press, 2018.

24 Barber S, Moreno-Leguizamon CJ. Can narrative medicine education contribute to the delivery of compassionate care? A review of the literature. Med Humanit 2017.

25 Chen I, Forbes C. Reflective writing and its impact on empathy in medical education: systematic review. J Educ Eval Health Prof 2014;11:20

26 Fioretti C, Mazzocco K, Riva S, et al. Research studies on patients' illness experience using the narrative medicine approach: a systematic review. BMJ Open 2016;6:e011220.

27 Laskow T, Small L, Wu DS. Narrative interventions in the palliative care setting: a scoping review. J Pain Symptom Manage 2019;58:696-706.

28 Milota MM, van Thiel GJMW, van Delden JJM. Narrative medicine as a medical education tool: a systematic review. Med Teach 2019;41:802-10.

29 Schoonover KL, Hall-Flavin D, Whitford K, et al. Impact of poetry on empathy and professional burnout of health-care workers: a systematic review. J Palliat Care 2019;825859719865545.

30 Goyal RK, Charon R, Lekas H-M, et al. 'A local habitation and a name': how narrative evidence-based medicine transforms the translational research paradigm. J Eval Clin Pract 2008;14:732-41.

31 Cochrane Handbook for systematic reviews of interventions, 2019. Available: http://handbook-5-1.cochrane.org/

32 Moher D, Liberati A, Tetzlaff J, et al. Preferred reporting items for systematic reviews and meta-analyses: the PRISMA statement. PLoS Med 2009;6:e1000097.

33 Arntfield SL, Slesar K, Dickson J, et al. Narrative medicine as a means of training medical students toward residency competencies. Patient Educ Couns 2013:91:280-6.

34 Aronson L, Schwalbe W. The art and craft of writing for self-care and narrative advocacy: a workshop in reflective and public writing (p11). J Pain Symptom Manage 2015;49:322.

35 Ball SC. Enhancing medicine subinternship through narrative medicine. J Gen Intern Med 2011;26.

36 Balmer D, Gill A, Nuila R. Integrating narrative medicine into clinical care. Med Educ 2016;50:581-2.

37 Balmer DF, Richards BF. Faculty development as transformation: lessons learned from a process-oriented program. Teach Learn Med 2012;24:242-7.

38 Bhavaraju VL, Miller S. Faculty development in narrative medicine: using stories to teach, learn, and thrive. J Grad Med Educ 2014;6:355-6.

39 Birigwa SN, Khedagi AM, Katz CJ. Stop, look, listen, then breathe: the impact of a narrative medicine curriculum on pediatric residents (descriptive Abstract). Acad Pediatr 2017;17:e40-1.

40 Bobb SJ. Finding meaning and sense-making in hospital nursing teams: the promise of narrative medicine. US: Marquette University, 2017.

41 Boudreau JD, Liben S, Fuks A. A faculty development workshop in narrative-based reflective writing. Perspect Med Educ 2012;1:143-54

42 Liben S, Chin K, Boudreau JD, et al. Assessing a faculty development workshop in narrative medicine. Med Teach 2012;34:e813-9.

43 Brigley S, Jasper M. Evaluation of a multidisciplinary faculty to support learning in surgical practice. $J$ Interprof Care 2010;24:401-11.

44 Chretien KC, Swenson R, Yoon B, et al. J Gen Intern Med 2014:29:S534-5.

45 Chretien KC, Swenson R, Yoon B, et al. Tell me your story: a pilot narrative medicine curriculum during the medicine clerkship. $J$ Gen Intern Med 2015;30:1025-8.

46 DasGupta S, Meyer D, Calero-Breckheimer A, et al. Teaching cultural competency through narrative medicine: intersections of classroom and community. Teach Learn Med 2006;18:14-17.
47 Elliott D, Schaff P, Woehrle T, et al. Narrative Reflection in Family Medicine Clerkship - Cultural Competence in the Third Year Required Clerkships. MedEdPORTAL Publications 2010;6.

48 Schaff P. Donning the white coat: the narrative threads of professional development. J Learn Through the Arts 2006;2.

49 Goodrich TJ, Irvine CA, Boccher-Lattimore D. Narrative Ethics as Collaboration: A Four-Session Curriculum. Families, Systems, \&amp. Health 2005;23:348-57.

50 Gordon E. Echoes of burnout in internal medicine resident narrative essays. J Gen Intern Med 2017;32:S171-2.

51 Goupy F, Abgrall-Barbry G, Aslangul E, et al. Can narrative medicine be an answer to patient physician relationship teaching according to students' demand in medical education curricula? Presse Med 2013;42:e1-8.

52 Gowda D, Balmer D, Khedagi A, et al. Year-Long narrative medicine intervention to improve interprofessional practice in three primary care practices. J Gen Intern Med 2017;32.

53 Heller EA, Heller FE. Narrative medicine: a practical application for using writing as a clinical intervention with cancer patients, caregivers and the clinicians that care for them. Psychooncology 2016;25:10

54 Hellerstein DJ. "The City of the Hospital": On Teaching Medical Students to Write. J Med Humanit 2015;36:269-89.

55 Holub PG. The influence of narrative in fostering affective development of medical professionalism in an online class. US: Nova Southeastern University, 2011

56 Hurst M, Irvine C. Stories of the end: A narrative medicine curriculum to reframe death and dying. In: Our changing journey to the end: Reshaping death, dying, and grief in America: New paths of engagement; New venues in the search for dignity and grace, Vols. 1-2. Santa Barbara, CA, US: Praeger/ABC-CLIO, 2014: 85-99.

57 Jacobs ZG, Sgro G. Pittsburgh narratives: a multidisciplinary workshop in narrative medicine. J Gen Intern Med 2017:32:S697-8.

58 Kennedy AJ, Sgro G. Birmingham voices: developing narrative competency to better serve vulnerable populations. J Gen Intern Med 2016;31.

59 Kissler MJ, Saxton B, Nuila R, et al. Professional formation in the gross anatomy lab and narrative medicine: an exploration. Acad Med 2016;91:772-7.

60 Lane-Reticker A, Fogel C. Introducing a humanities focus into a curriculum for Midcareer HPM trainees (744). J Pain Symptom Manage 2012;43:446.

61 Machado MdoC, Lobo Antunes J. Narrativa dA Doença: Uma Disciplina Optativa Na Faculdade de medicina de Lisboa. Acta Med Port 2016;29:790-2.

62 San Julian Mark M, Todd K, Todd D. The language of illness: the art of telling, listening, and self-care through narrative medicine (TH314). J Pain Symptom Manage 2017;53:321-2.

63 Moss HA, Winkel AF, Jewell A, et al. Narrative medicine: using reflective writing workshops to help house staff address the complex and challenging nature of caring for gynecologic oncology patients. Gynecol Oncol 2014:133:73.

64 Murrinson B. Pain and the humanities: exploring the meaning of pain in medicine through drama, literature, fine arts and philosophy. MedEdPORTAL Publications 2010;6.

65 Polvani S, Mammucari M, Zuppiroli A, et al. Narrative medicine, a model of clinical governance: the experience of the local health authority of Florence in Italy. Clinical Practice 2014;11:493-9.

66 Roy R. Teaching cultural sensitivity through literature and reflective writing. Virtual Mentor 2007;9:543-6.

67 Shankar PR. A voluntary medical humanities module in a medical college in Western Nepal: participant feedback. Teach Learn Med 2009;21:248-53.

68 Spike J. 'On doctoring': essays on professionalism. MedEdPORTAL Publications 2008:4.

69 Walker MR, Zúñiga D, Triviño X. Narrativa $Y$ formación docente: La experiencia de 5 años de un taller de escritura. Rev. méd. Chile 2012;140:659-66.

70 Winkel A. Narrative medicine: a writing workshop curriculum for residents. MEP 2016;12.

71 Winkel AF, Hermann N, Graham MJ, et al. No time to think: making room for reflection in obstetrics and gynecology residency. J Grad Med Educ 2010;2:610-5.

72 Wohlmann A, Halstein M. Narrative Medizin: ein Pilotprojekt Im skills lab Der Universitätsmedizin Mainz. ZFA 2016:92:456-60.

73 Zohouri M, Amini M, Sagheb MM. Fourth year medical students reflective writing on "Death of Ivan llych": a qualitative study. $J$ Adv Med Educ Prof 2017;5:73-7.

74 Adamson K, Sengsavang S, Charise A, et al. Narrative training as a method to promote nursing empathy within a pediatric rehabilitation setting. J Pediatr Nurs 2018;42:e2-9. 
75 Casapulla SL, Bianco JA, Harter LM, et al. Moving toward narrative competence and inclusive healthcare through the open book project. Health Commun 2018:1-5.

76 Cunningham $\mathrm{H}$, Taylor D, Desai UA, et al. Looking back to move forward: first-year medical students' Meta-Reflections on their narrative portfolio writings. Acad Med 2018;93:888-94.

77 Hinyard LJ, Wallace CL, Ohs JE, et al. Narrative medicine and reflective practice among providers: connecting personal experiences with professional action for ACP. JCO 2018;36:9.

78 Gottlieb S, Jaglom L, Bialik I, et al. A humanities curriculum in a pediatric training program. Acad Pediatr 2018;18:e25-6.

79 Kirkland KB, Craig SR. Exploring the surgical gaze through literature and art. JAMA 2018;319:1532-4.

80 Shaw AC, McQuade JL, Reilley MJ, et al. Integrating Storytelling into a communication skills teaching program for medical oncology fellows. J Cancer Educ 2018.

81 Wesley T, Hamer D, Karam G. Implementing a narrative medicine curriculum during the internship year: an internal medicine residency program experience. Perm J 2018;22.

82 Yang N, Xiao H, Cao Y, et al. Does narrative medicine education improve nursing students' empathic abilities and academic achievement? A randomised controlled trial. J Int Med Res 2018:46:3306-17.

83 Forner K, Marchand L, Ingram C. "Too Good to be True? No!" Exploring Self, Incorporating a Quick and Easy Reflective Writing Exercise that Anyone Can Do (TH339). J Pain Symptom Manage 2019;57:383.

84 Gowda D, Curran T, Khedagi A, et al. Implementing an interprofessional narrative medicine program in academic clinics: feasibility and program evaluation. Perspect Med Educ 2019;8:52-9.

85 Harrison MB, Chiota-McCollum N. Education research: an arts-based curriculum for neurology residents. Neurology 2019;92:e879-83.

86 Richardson DR, Winzelberg G, Rosenstein DL, et al. Development of an "Art of Oncology" curriculum to mitigate burnout and foster solidarity among hematology/oncology fellows. J Clin Oncol 2019;37.

87 Rivlin K, Westhoff CL. Navigating uncertainty: narrative medicine in pregnancy options counseling education. Patient Educ Couns 2019;102:536-41.

88 Rosenberg N, Vitez M. Jamaica Kincaid's "Girl" and the Challenge of Growing Up in Medical Training. JAMA 2019;322:1238-9.

89 Whitesides LW, McAdams M, Quinn S, et al. The role of narrative medicine as a means of reflection among internal medicine interns. $J$ Gen Intern Med 2019;34.

90 Small LC, Feldman LS, Oldfield BJ. Using narrative medicine to build community across the health professions and foster self-care. J Radiol Nurs 2017;36:224-7.

91 Spike J. Patient-Centered medicine: writing your patient's life story. MedEdPORTAL Publications 2008;4.

92 Robeson R, King NMP. Performable case studies in ethics education. Health Care 2017;5:57.

93 Kuper A. Literature and medicine: a problem of assessment. Acad Med 2006;81:S128-37.
94 Doukas DJ, McCullough LB, Wear S. Project to R, integrate medical education I. perspective: medical education in medical ethics and humanities as the foundation for developing medical professionalism. Acad Med 2012;87:334-41.

95 Steinert Y, McLeod PJ, Liben S, et al. Writing for publication in medical education: the benefits of a faculty development workshop and peer writing group. Med Teach 2008;30:e280-5.

96 Sonnad SS, Goldsack J, McGowan KL. A writing group for female assistant professors. J Nat/ Med Assoc 2011;103:811-5.

97 Brandon C, Jamadar D, Girish G, et al. Peer support of a faculty "writers' circle" increases confidence and productivity in generating scholarship. Acad Radiol 2015;22:534-8.

98 Pololi L, Knight S, Dunn K. Facilitating scholarly writing in academic medicine. J Gen Intern Med 2004;19:64-8.

99 Dankoski M, Palmer M, Banks J, et al. Academic writing: supporting faculty in a critical competency for success. J Faculty Develop 2012;26:47-54.

100 AAMC. Burnout among U.S. medical school faculty. AAMC Analysis in Brief 2019;19.

101 Zhang Y-Y, Han W-L, Qin W, et al. Extent of compassion satisfaction, compassion fatigue and burnout in nursing: a metaanalysis. J Nurs Manag 2018;26:810-9.

102 Dugani S, Afari H, Hirschhorn LR, et al. Prevalence and factors associated with burnout among frontline primary health care providers in low- and middle-income countries: a systematic review. Gates Open Res 2018;2.10.12688/gatesopenres.12779.1

103 Shanafelt TD, Hasan O, Dyrbye LN, et al. Changes in burnout and satisfaction with work-life balance in physicians and the general us working population between 2011 and 2014. Mayo Clinic Proceedings 2015;90:1600-13.

104 Tijdink JK, Vergouwen ACM, Smulders YM. Emotional exhaustion and burnout among medical professors; a nationwide survey. BMC Med Educ 2014;14:183.

105 IsHak W, Nikravesh R, Lederer S, et al. Burnout in medical students: a systematic review. Clin Teach 2013;10:242-5.

106 Cunningham T. The use and role of narrative practices to mitigate compassion fatigue among expatriate health workers during the Ebola outbreak of 2013-2016. US: Columbia University, 2017.

107 Hunt MR, Schwartz L, Sinding C, et al. The ethics of engaged presence: a framework for health professionals in humanitarian assistance and development work. Dev World Bioeth 2014;14:47-55.

108 Johnson DR. Transportation into a story increases empathy, prosocial behavior, and perceptual bias toward fearful expressions. Pers Individ Dif 2012;52:150-5.

109 Pasco JC, Anderson C, DasGupta S. Visionary medicine: speculative fiction, racial justice and Octavia Butler's 'Bloodchild'. Med Humanit 2016;42:246-51.

110 Saffran L. What Pauline Doesn't Know: Using Guided Fiction Writing to Educate Health Professionals about Cultural Competence. J Med Humanit 2017.

111 Barbour RS. Mixing qualitative methods: quality assurance or qualitative quagmire? Qual Health Res 1998;8:352-61. 